\title{
A Connected Steady-State Thermal with a Structural Analysis using FEA in ANSYS
}

\author{
Gavril Grebenisan ${ }^{1}$, G Grebenişan ${ }^{2}$, D C Negrău ${ }^{2}$, and N Salem³ \\ ${ }^{1}$ Affiliation not available \\ ${ }^{2}$ Industrial Engineering Department, University of Oradea \\ ${ }^{3}$ Mechanical Engineering Department, Zarqa University
}

February 15, 2022

\section{Hosted file}

A Connected Steady-State Thermal with a Structural Analysis using FEA in ANSYS.pdf available at https : //authorea .com/users/460244/articles/556287-a-connected-steady-state-thermalwith-a-structural-analysis-using-fea-in-ansys 